\title{
DIÁSPORA E OS ESPAÇOS MNEMÔNICOS EM "SAGA DE AGOTIME, MARIA MINEIRA NAÊ"
}

\author{
DIASPORA AND MNEMONIC PLACES IN "SAGA DE AGOTIME, MARIA \\ MINEIRA NAÊ",
}

\author{
Recebido: 14/05/2020 | Aprovado: 15/06/2020 | Publicado: 10/07/2020 \\ DOI: https://doi.org/10.18817/rlj.v4i1.2239
}

\begin{abstract}
Risoleta Viana de Freitas ${ }^{1}$
Orcid ID: https://orcid.org/0000-0002-2437-7000
\end{abstract}

Rayron Lennon Costa Sousa²
Orcid ID: https://orcid.org/0000-0002-7052-0031

Resumo: Homi Bhabha, em O local da cultural (2013), dentre outros aspectos, discute os universos que entrecruzam a diáspora e respondem por ela, especificamente os efeitos da dispersão de povos, seja por vontade própria do sujeito ou forçada, como é o caso dos negros escravizados, que, apartados de seus lugares de origem, precisaram reconstituir-se em outros espaços. Assim, considerando as Áfricas (re)criadas nesses espaços diaspóricos, a exemplo, a cidade do Rio de Janeiro, a Escola de Samba Beija-Flor de Nilópolis tematizou e ilustrou, através de indumentárias e músicas, os movimentos de trânsito dos negros no Brasil. Nesse sentido, objetivamos compreender o processo diaspórico e os espaços mnemônicos a partir da tematização da África no samba-enredo em "Saga de Agotime, Maria Mineira Naê", apresentado no desfile carnavalesco de 2001. As reflexões teóricas perpassam as ideias de Maurice Halbwachs (2006) - no tocante às reflexões acerca da memória individual e coletiva; Homi Bhabha (2013), Mortari (2015) - com referenciais sobre diáspora; Aleida Assmann (2011), acerca dos espaços que permeiam a recordação e a memória, dentre outros. A partir da análise cunhada, intentamos demonstrar que, uma vez deslocados de suas raízes, os negros valeram-se de variados mecanismos, especificamente, da memória e dos lugares que possibilitam o acionamento desses aspectos como elementos de ressignificação de si, de sua terra, bem como dos novos espaços que passaram a ocupar e ressignificar.

Palavras-chave: A saga de Agotime. Maria Mineira Naê. Samba-enredo. Diáspora. Espaços Mnemônicos.

Abstract: In The location of culture (2013), among other aspects, Homi Bhabha discusses the spaces that intertwine diaspora and answer for it, specifically the effects of the dispersion of peoples, whether by their own will or by force, such as the case of enslaved Black people, who

1 Professora Substituta da Universidade Estadual do Maranhão - UEMA, Campus Caxias. Doutoranda em Literatura pela Doutorando em Literatura pela Universidade Federal do Piauí UFPI. Mestra em Letras pela Universidade Estadual do Piauí. Especialista em Literatura e Ensino e Graduação em Letras / Português, ambas titulações pela Universidade Estadual do Maranhão. É integrante do Grupo de Pesquisa Teseu, o labirinto e seu nome (UFPI) e do Grupo Americanidades: lugar, diferença e violência.E-mail: risoleta.rfreitas@gmail.com

${ }^{2}$ Professor Assistente da Universidade Federal do Maranhão - UFMA, Campus São Bernardo. Doutorando em Literatura pela Universidade Federal do Piauí - UFPI, Mestre em Teoria Literária pela Universidade Estadual do Maranhão - UEMA. Graduado em Letras - Português/Espanhol e respectivas literatura pela Universidade do Tocantins - UNITINS. Vice-Coordenador do Grupo de Pesquisa em Literatura, Alteridade e Decolonialidade - GPLADe, vinculado à UFMA; Membro do Grupo de Pesquisa em Historiografia, Cânone e Ensino, vinculado à Universidade de Brasília UnB e Membro do Grupo de Pesquisa em Literatura, Leitura e Ensino, vinculado à Universidade Estadual do Piauí - UESPI. E-mail: rayronsousa@hotmail.com 
needed to reconstitute themselves in other places after being dispersed from their place of origin. Thus, considering the Africas that were (re)created in different places, such as the city of Rio de Janeiro, the Beija-Flor de Nilópolis Samba School chose as a theme, to illustrate through costumes and music, the traffic movements of Black people in Brazil. Considering this, we aim to understand the diáspora process and mnemonic places through the presentation of Africa in the samba-plot "Saga de Agotime, Maria Mineira Naê", from the 2001 Carnival parade in Brazil. Theoretical reflections in this study are based on the ideas of Maurice Halbwachs (2006) regarding the reflections on individual and collective memory; Homi Bhabha (3013) and Mortari (2015) - as references about the diaspora issue; Aleida Assmann (2011) - about the spaces that cross remembrance and memory; and other authors. The results of this analysis show that, once displaced from their roots, Black people used different mechanisms, specifically: memory, the places that would activate aspects as elements of resignification of themselves, their land, as well as new spaces that they started to occupy and reframe.

Keywords: Agotime Saga. Maria Mineira Naê. Samba-plot. Diaspora. Mnemonic places.

\title{
Palavras iniciais
}

\author{
Atravessamos o mar Egeu \\ Um barco cheio de Fariseus \\ Com os Cubanos \\ Sírios, ciganos \\ Como Romanos sem Coliseu \\ (Diáspora, Tribalista)
}

Os versos da canção "Diáspora", interpretados pelo trio Tribalistas composto pelos cantores e compositores Arnaldo Antunes, Carlinhos Brown e Marisa Monte, apresentam-nos o drama vivenciado pelos refugiados que, nas águas do Mar Egeu, em barcos onde também estavam cubanos, sírios e ciganos, fizeram a travessia diaspórica, deixando suas raízes, rumo a lugares novos e desconhecidos. De maneira forçada, via de regra, esses sujeitos experienciaram o deslocamento, o desenraizamento, cujas ancestralidades, suas histórias, bem como as culturas envolvidas passaram a existir apenas no corpo e na memória.

A partir dos trânsitos e da multiplicidade de relatos desses viajantes involuntários, ao longo da História percebemos por meio da literatura, da música, bem como de outras artes que não apenas cubanos, sírios, ciganos, italianos atravessaram as águas de mares e oceanos em condições de sujeitos diaspóricos. Milhares de mulheres e homens negros, em situação de aprisionados e escravizados foram obrigados a deixar seus lugares de origem para, dentro dos navios negreiros, em condições desumanas, desembarcarem em terras novas, como a exemplo, da América, pelas rotas do Atlântico, que pelas idas e vindas, na perspectiva decolonial, passou a se chamar Atlântico Negro. Assim, a tarefa de 
compreender como esse processo foi vivenciado é algo imprescindível na luta contra invisibilização e desumanização desses sujeitos que, destituídos de sua história, de sua cultura e de suas ancestralidades recorreram à memória para reconstruírem-se.

Dessa forma, o presente artigo se debruça sobre o corpus, o sambaenredo “A Saga de Agotime, Maria Mineira Naê", apresentado em 2001 pela Escola de Samba Beija-Flor de Nilópolis, a qual tematizou a trajetória de Agotime, mulher negra, aprisionada, escravizada e transportada da África ao Brasil, cujo destino final foi o Maranhão, local onde encontrou escravos jejes ${ }^{3}$ e fundou a Casa das Minas $^{4}$, recebendo, a partir de então, o nome de Maria Mineira Naê. A partir desse contexto, objetivamos compreender o processo diaspórico de Agotime - Maria Mineira Naê e os espaços mnemônicos por ela rememorados a partir da tematização da África no samba-enredo em questão.

A partir de uma abordagem bibliográfica e interpretativa, as discussões desenvolvidas nesta pesquisa, considerando os aspectos relacionados, têm fundamentação em Halbwachs (2006) - no que tange às reflexões acerca da memória individual e coletiva; Stuart Hall (2003; 2006), Homi Bhabha (2013) - com referenciais sobre diáspora; Aleida Asmann (2011), acerca dos espaços que permeiam a recordação, a memória, dentre outros autores.

Portanto, a partir do diálogo entre o referencial teórico selecionado e as análises, as reflexões demonstraram que, uma vez deslocados de suas raízes, num movimento diaspórico, os negros utilizaram-se de variados mecanismos, especificamente, da memória, dos lugares que possibilitam o acionamento de suas vivências e de sua ancestralidade como elementos de ressignificação de si, de sua terra, bem como dos novos espaços que passaram a ocupar e reconstruir, muitas vezes com o sentimento de deslocamento, como fez Agotime, no Maranhão, ao ressignificar suas heranças culturais "através da construção de novas identidades", o que fez com ela voltasse a ser Rainha; "[..] de formas de devoção" (MORTARI, 2015, p. 134-135), sendo até os dias de hoje a Casa das

\footnotetext{
3“Tribo da cultura Ewefon, introduzida no Brasil através do tráfico de escravos vindos do Dahomey". Disponível em: https://www.templodovaledosoledalua.org.br/pequeno-dicionarioyoruba-x-portugues/. Acesso em 17/07/2019

${ }^{4}$ É um terreiro de religião africana mais antigo de São Luís do Maranhão, que fora fundado no século XIX.
} 
Minas, em São Luís, um dos espaços da memória e da ancestralidade do povo africano.

\section{Samba-enredo: a origem e a saga do subgênero musical}

De acordo com os escritores Alberto Mussa e Luiz Antonio Simas, em Samba de enredo (2010), "[...] a cultura popular brasileira é repleta de manifestações que se expressam no formato processional [...]" (MUSSA; SIMAS, 2010, p. 11), ou seja, procissões, e citam como exemplos os festejos realizados em várias regiões do país ${ }^{5}$. Ainda para os estudiosos, o caráter de procissão desses festejos pode ser relacionado às festividades realizadas em comemoração aos dias de Momo, ou seja, o carnaval, que ao longo do tempo foi adquirindo grandes proporções e incorporando novas características.

Segundo os autores mencionados, os antigos carnavais - os desfiles de ruas -, os blocos improvisados, os ranchos - foram sofrendo transformações, culminando no que hoje conhecemos como símbolo de expressão da cultura brasileira, o carnaval, especificamente o das cidades de São Paulo e Rio de Janeiro, que se revezam com os desfiles das grandes Escolas de Samba. Nesse sentido, podemos relacionar a origem do samba-enredo, enquanto subgênero do samba, ao universo do carnaval. Cabe destacar, nesse contexto discurso, que o samba era restrito às casas das baianas residentes no Rio de Janeiro, mas ao passo que se ressignificava, ganhando outras proporções, passou a ter adeptos nas ruas.

Carlos Sandroni, em Feitiço decente: transformações do samba no Rio de Janeiro (1917-1930), concebe a existência de duas tipologias de samba nas primeiras décadas do século XX, no Rio de Janeiro. Na primeira, o samba era cultuado nas casas das baianas, a exemplo, na casa de Tia Ciata; na segunda, no início da década de 1930, ele foi desenvolvido no bairro Estácio de Sá, passando a ser considerado o estilo musical cultuado pelas escolas de samba, ou seja, o samba-enredo, subgênero do samba. Nessa assertiva, o autor discorre que:

${ }^{5}$ Folia de Reis, festa católica iniciada em 24 de dezembro e finaliza em 6 de janeiro; Festejo de Nossa Senhora do Rosário, em 7 de outubro; Festejo de São Francisco de Assis, com início em setembro, culminando em 04 de outubro; Festa de Nossa Senhora Aparecida, celebrada em 12 de outubro, dentre tantas outras festividades dedicadas aos santos e à santas. 
[...] O tipo mais antigo é associado a Tia Ciata e aos compositores que frequentavam sua casa, como Donga, João da Baiana, Sinhô, Caninha, Pixiguinha. O tipo mais recente é associado a um bairro do Rio de Janeiro - chamado Estácio de Sá, ou simplesmente Estácio (em homenagem ao português que fundou a cidade em 1565) - e aos compositores que ali viviam ou circulavam: Ismael Silva, Nilton Bastos, Bide (Alcebíades Barcelos), Brancura (Sílvio Fernandes) e outros. O tipo de samba que teria sido criado no Estácio logo se difundiu, influenciando os compositores de outras áreas da cidade, generalizando-se e tornando-se um sinônimo de samba moderno, de samba tal qual o reconhecemos hoje em dia. A primazia do Estácio sobre os outros redutos do samba carioca é admitida por todos (SANDRONI, 2012, p. 133).

A partir da discussão do autor, entende-se a transformação ocorrida dentro do samba, originando um subgênero - o samba-enredo-, pela necessidade de ritmos e batidas mais aceleradas, capazes de empurrar e acompanhar a multidão, haja vista a saída do samba, antes restrito às casas das baianas e às rodas de conversas entre amigos, para as ruas. Assim, podemos compreender o samba-enredo, não somente como subgênero musical, mas como elemento inerente ao universo carnavalesco, item, inclusive, constituinte do grupo de aspectos a serem julgados durante o desfile.

Corroborando tais afirmações, Nei Lopes e Luiz Antonio Simas em Dicionário história social do samba (2015), ao discorrerem sobre o verbete samba-enredo, expõem outros aspectos que estão atrelados às transformações do samba e à organização dos desfiles:

O carnaval das escolas de samba cariocas - cujos terreiros (e não 'quadras', como depois denominaram) até cerca dos anos 1970 obedeciam a um regimento tácito semelhante, por exemplo, ao dos barracões do candomblé [...]. Os primeiros exemplares do subgênero samba-enredo eram obras de criação livre e falavam, geralmente, da natureza, do próprio samba e do cotidiano dos sambistas. Com a oficialização dos concursos, na década de 1930, passou a predominar, como eixo temático, a exaltação dirigida aos personagens históricos e efemérides exemplares dos currículos escolares. Os enredos, então, limitavam-se a contar a história do ponto de vista das elites senhoriais dirigentes, abordando os acontecimentos de forma invariavelmente nostálgica e ufanista. Mas uma reversão desse quadro começou a ganhar contornos mais efetivos em 1959. [...] (LOPES; SIMAS, 2015, p. 17-18).

Com base nas assertivas desses autores, percebemos a relação do desfile dos ranchos, dos blocos e, posteriormente, das atuais escolas de samba com as procissões das quais falam Musa e Simas (2010). Desse modo, além do 
caráter processional da festa, Lopes e Simas (2015) desvelam as intenções que sustentam a construção do enredo, do samba-enredo, bem como de toda estruturação do carnaval, incluindo as agremiações carnavalescas.

A partir do surgimento e consolidação do subgênero em discussão, os concursos realizados até hoje, especificamente nos dias de Momo, passaram a adotar temáticas específicas nos seus enredos, entrelaçando enredo e samba, tendo este último uma relação de continuidade daquele, por esta razão, sua junção - o samba-enredo. Na historiografia do gênero, a partir de $1959^{6}$, fugindo de temáticas ufanistas e que representavam o pensamento dos dirigentes da sociedade carioca - a elite -, as escolas de samba começaram, por meio do carnavalesco ou das comissões de carnaval, a apresentar temáticas diversas em seus enredos, dentre as quais citamos o Grêmio Recreativo e a Escola de Samba Beija-Flor de Nilópolis, por tematizarem o negro, a África e suas essências culturais, bem como os produtos resultantes da diáspora.

A fundação da Escola de Samba Beija-Flor de Nilópolis, cabe salientar, data de 1948. Em dezembro daquele ano, tem origem o bloco carnavalesco conhecido como a Associação Carnavalesca Beija-Flor, ou simplesmente Bloco Beija-Flor, uma idealização de Milton de Oliveira (Negão da Cuíca), Edson Vieira Rodrigues (Edinho do Ferro Velho), Helles Ferreira da Silva, Walter da Silva, Hamilton Floriano e José Fernandes da Silva. A transformação do bloco em escola de samba dá-se em 1953, quando este fora inscrito, por Silvestre David dos Santos, na Confederação das Escolas de Samba para o desfile de 1954, já com o nome pela qual é conhecida atualmente.

Ao longo dos anos, mais de setenta (70) anos, para sermos precisos, a escola nilopolitana tem apresentado ao público, por meio dos sambas-enredos, diferentes temáticas que abordam as mais diversas questões e problemas que permeiam a sociedade. Assim, sendo uma das precursoras no trabalho com as

\footnotetext{
${ }^{6}$ Segundo Lopes e Simas, em 1959, o GRE Salgueiro foi um dos pioneiros em apresentar enredo diferente. A escola "apresentou, com uma homenagem ao pintor francês Debret, o cotidiano dos negros no Brasil à época da Colônia e do Império, o que motivou na mesma escola, uma sequência de enredos, ao longo da década de 1960, como Quilombo dos Palmares, Chica da Chica, Aleijadinho e Chico Rei, voltados para o continente africano" (LOPES; SIMAS, 2015, p. 18). Além do Salgueiro, outras escolas, daquela década em diante, apresentaram enredos tematizando esse continente, quais sejam: Viradouro, em 1967, com o enredo "Chico Rei"; Beija-Flor de Nilópolis, em 1978, com "A criação do mundo na tradição Nagô; em 1988, "Sou negro, do Egito à liberdade, bem como com o enredo neste artigo analisado, dentre ouros.
} 
temáticas emergentes, o samba-enredo selecionado para este artigo é intitulado "A saga de Agotime: Maria Mineira Naê", de autoria de Déo, Caruso, Cleber e Osmar, apresentado no ano de 2001, pela escola citada acima, o qual traz como temática principal a saga vivenciada por Agotime, rainha africana, aprisionada e escravizada. A protagonista vivenciou a travessia diaspórica nos porões dos navios de tráfico vindos da África. Escravizada no Brasil, fundou no estado do Maranhão, a Casa das Minas, espaço em que vemos a ressignificação das matrizes religiosas cultuadas na África, originando as práticas afro-brasileiras, tais como a Umbanda e o Candomblé, manifestações resultantes do processo diaspórico.

Podemos perceber, no samba-enredo em análise, a partir das justificativas, a escravidão, o tráfico de negros e a dispersão deles em vários lugares da América, como é o caso do Brasil. Na direção desses movimentos, revisitamos as acepções de Bhabha (2013), no tocante à diáspora e a disseminação de povos, incutindo, desse modo, que os sujeitos diaspóricos vivem numa luta e numa busca constantes pela sobrevivência e pela ressignificação de suas tradições em diferentes lugares, distantes das terras africanas, como percebemos no refrão abaixo:

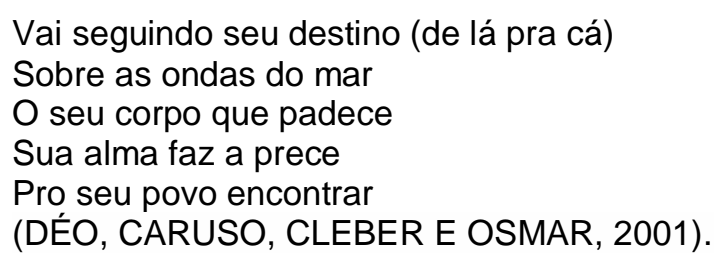

As estrofes selecionadas são repetidas várias vezes no samba-enredo, na tentativa de representar, simbolicamente, as inúmeras travessias nas quais os africanos foram submetidos, translados pelo oceano Atlântico Negro, imensidão essa que mergulhou profundamente muitos corpos que desistiram de resistir, nas travessias até o território brasileiro. Discorre-se, ainda, sobre o exílio de seus territórios de origem e a exploração de suas mãos de obra [a escravidão], o que resultou na diáspora negra, que Paul Gilroy (2012) vê como um "aspecto transnacional", havendo trânsito entre nações e um aspecto intercultural.

Percebemos que o negro africano e sua ancestralidade, via Rainha Agotime, após ser aprisionada e escravizada, demarca o entrecruzamento não 
apenas entre continentes e países, mas identifica culturas sendo traduzidas, sendo experimentadas e ressignificadas. Ainda, enquanto negra e em travessia pelo Atlântico, Agotime sofre vários processos de violências, tanto física, quanto psicológica e moral, de tal modo que, como afirma Glissant (2015), resta um corpo nu, destituído de toda subjetividade e de humanidade, essa última carregando consigo os rastros e os resíduos dos acontecimentos vividos no passado.

$\mathrm{Na}$ perspectiva do corpo nu, violentação corporificada sobre Agotime, assim como tantos/as negros/as traficados/as para a avenida do samba por meio dos sambas-enredos, esses(as) sujeitos(as) possuem tão somente a memória como mecanismo capaz de trazer sentidos novos, acervo de experiências esse que nem sempre trará boas recordações, pois os espaços percorridos, os lugares vividos também são lembrados, que pode causar dor, sofrimento, além do desejo de regresso ao passado, como percebe-se no romance abolicionista Úrsula (1859), de Maria Firmina dos Reis, no qual a personagem Preta Susana evoca inúmeras vezes a Mãe África com o desejo de regresso, apesar de todas as mazelas de sua pátria mãe.

Portanto, considerando a caminhada discursiva sobre as representações resultantes da diáspora, para Glissant, esses sujeitos [diaspóricos] guardam em sua memória, "[...] os cantos entoados nos funerais, casamentos, batismos, que expressam a dor, a alegria, vindos do antigo país de origem, e que são cantados há cem anos ou mais, em diversas ocasiões da vida familiar (2005, p. 19-20), ou seja, guardam também a sua ancestralidade e revisitam-na inúmeras vezes durante a vida. Desse modo, temos o indivíduo rememorando fatos e acontecimentos experienciados individual e coletivamente, como veremos no tópico seguinte.

\section{Diáspora e os espaços mnemônicos em "A saga de Agotime, Maria Mineira Naê"}

Homi Bhabha, no capítulo "DissemiNação" integrante de O Local da cultura (2013), discorre sobre o processo de deslocamento de povos, e inicia, 
relatando sua experiência e vivência como sujeito dispersado. A despeito dessa questão, O crítico assim expõe:

\begin{abstract}
Vivi aquele momento de dispersão de povos que, em outros tempos e em outros lugares, nas nações de outros, transforma-se num tempo de reunião. Reunião de exilados, émigres e refugiados, reunindo-se às margens de culturas "estrangeiras", reunindo-se nas fronteiras; reuniões nos guetos ou cafés de centro da cidade, reunião na meia-vida, meia-luz de línguas estrangeiras, ou na estranha fluência da língua do outro; reunindo os signos de aprovação e aceitação, títulos, discursos, disciplinas, reunindo as memórias de subdesenvolvimento, de outros mundos vividos retroativamente, reunindo 0 passado num ritual de revivescência, reunindo o presente. (BHABHA, 2013, p. 227).
\end{abstract}

De acordo com a citação do autor, percebemos, então, que os sujeitos deslocados, também chamados de diaspóricos, ao tempo que habitam vários espaços - sejam as fronteiras, os guetos, as ruas -, não se desvencilham do seu lugar de origem, e necessitam lidar com as experiências do outro lugar, ou do lugar do outro, com trocas de experiências resultantes do contato com sujeitos distintos, que podem ou não ser oriundos do mesmo país, o que gera, consequentemente, o compartilhamento de ideias, de conhecimentos e de costumes.

Ainda conforme Bhabha (2013), o vínculo com o lugar de origem, forçadamente deixado, permanece e é ressignificado pela memória do sujeito. São as vivências e fatos experienciados no passado que se entrelaçam ao presente, no que o autor denomina como "ritual de revivescência". Desse modo, o sujeito diaspórico mantém vivo os laços com sua ancestralidade e com suas práticas culturais, já que toda materialidade que poderia estabelecer esse laço the destituía nos porões dos navios negreiros.

A partir dessas acepções, ao refletir sobre o processo diaspórico de povos, Claudia Mortari no artigo Experiências das populações africanas e afrodescendentes na diáspora brasileira, publicado em 2015, argumenta que,

[...] a diáspora africana não significa, na nossa concepção, apenas o deslocamento forçado, porém, a redefinição histórica e social de pertencimento, perceptível através da construção de novas identidades e identificações, de formas de devoção, de rearranjos de sobrevivências históricas de lutas por autonomia e liberdade. (MORTARI, 2015, p. 134135). 
Segundo a autora, isso deve-se ao fato de que o processo de tráfico vivenciado pelos negros resultou na dispersão de muitos deles por toda a América, especialmente nos portos brasileiros, situados nos estados do Rio de Janeiro, Bahia e Maranhão, o que, de certo modo, possibilita o estreitamento das relações entre Brasil e África, em decorrência, também, do fluxo constante de:

[...] ideias, tecnologias, ritmos, visões de mundo e, também na construção e novas formas de viver a vida por parte dos africanos e seus descendentes no Brasil, cujas experiências históricas têm sido abordadas pelos historiadores: formas de trabalho, composição de laços de parentesco, Irmandades Religiosas, sociedades recreativas, produções artísticas, etc., tanto no contexto escravagista brasileiro quanto no pós-abolição (MORTARI, 2015, p. 134).

Destacamos, de acordo com a argumentação de Mortari, as práticas ou as irmandades religiosas, que figuram, dentre os aspectos, a possibilidade de estreitamento das relações entre o país, a cultura de origem do sujeito diaspórico e novo espaço para o qual foram destinados. Desse modo, levando em consideração tais assertivas, vemos que toda a letra da composição apresentada pela Beija-Flor de Nilópolis em 2001, desde o título já evidencia o processo de travessia, ou seja, transitoriedade, inclusive, identitária do sujeito que, disperso do mundo africano, busca reconstruir-se em outros espaços. Na narrativa que nos apresenta a vida da Rainha, vemos esses espaços materializados no continente americano, em terras brasileiras, Bahia e Maranhão, especificamente em São Luís, na Casa das Minas.

O sujeito diaspórico, apresentado no samba-enredo em voga neste artigo, serve de subsídio para que pensemos a trajetória de muitos outros negros que vivenciaram o processo de tráfico, de deslocamento, mergulhando nas vivências do que sofreram na e pela pele, incutindo os amálgamas do tráfico abordo nos porões dos navios, quando na travessia da África à América, desembarcavam no Brasil com diversos traumas, considerando que muitos foram despejados nos oceanos. Na estrofe que segue, é possível vislumbrar o início da saga diaspórica a que os negros foram submetidos - não bastavam-lhes apenas a dor causada pelo desenraizamento e o deslocamento em condições desumanas.

A busca por representar, simbolicamente, as trajetórias de dor, de medo e da tentativa de extermínio da população afro, a que tantos/as outros/as negros e 
negras, assim como a Rainha Agotime, foram submetidos, encarcerados e amontados como bichos nos navios que os transportavam pelo Atlântico, tornouse música, ecoada aos quatro cantos do mundo, num processo de revisitação memorialista e para o enaltecimento de suas matrizes ancestrais, conforme podemos analisar no fragmento que segue:

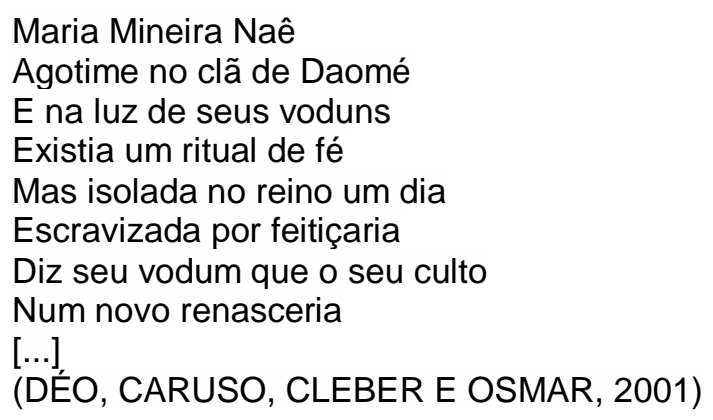

O último verso expressa que, embora isolada e escravizada, o renascer num novo era algo inevitável e uma certeza. Agotime encontrou-se com os Nagôs e através dos ancestrais africanos, teve conhecimento que seu povo, os "NegrosMinas" tinham sido levados para São Luís. A Rainha faz, num "ritual de fé", "a prece pro seu povo encontrar" (DÉO, CARUSO, CLEBER E OSMAR, 2001). E, por meio da religiosidade e da memória dos seus e de suas práticas, ressignificaria os seus costumes, fazendo surgir uma 'nova' África em solo brasileiro/maranhense, como pode-se discutir contemporaneamente como encontro diaspórico. Assim, conforme a Comissão de Carnaval da Beija-Flor, responsável por pensar enredo e todo o desfile,

O sofrimento físico da rainha, traída e humilhada era uma realidade menor pois seu espírito continuava liberto e sobre as ondas, sem grilhão, a rainha lidera um grande cortejo e atravessa o mar. Nasce a ligação África-Brasil. Chega ao novo continente um corpo escravo mas um espírito livre, pronto a cumprir a sua saga e fazer ouvir daqui o som dos tambores Jêjes. (COMISSÃO DE CARNAVAL, 2001, GALERIA DO SAMBA).

Ainda segundo a Comissão Carnavalesca, a também Feiticeira Agotime desembarcou na Bahia, onde encontrou muitos irmãos africanos, que assim como ela foram levados ao Maranhão, como é possível observar no trecho que segue:

$[\ldots]$

Chegou nessa terra santa

Bahia viu a nação nagô ô ô 


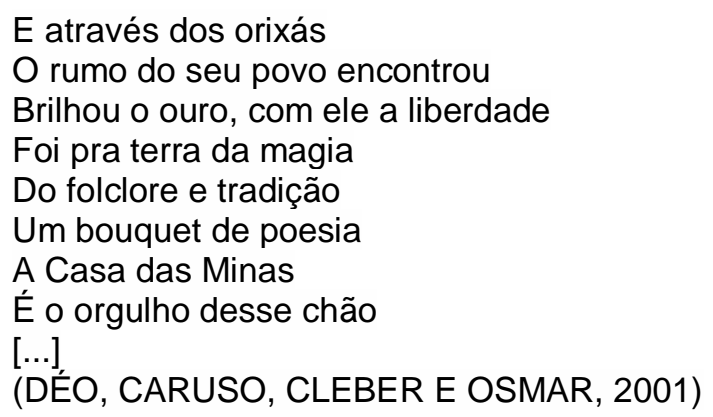

Analisando do fragmento, a terra da magia da qual fala o sexto verso é São Luís do Maranhão, onde fundou, por orientação dos orixás que recebia e cultuava, um templo de tambor, chamado de Casa das Minas. Por esta razão, Agotime - rainha e feiticeira africana - que experienciou o tráfico e a travessia no Atlântico, após ser escravizada, passa a ser Maria Mineira Naê, como heranças dos seus voduns por atendê-los e construir um espaço para cultuação e manifestação da religiosidade do povo africano, agora em terras brasileiras, produto da diáspora.

Para Aleida Assmann (2011), a memória refere-se a experiências variadas, além de ser considerada um veículo de transmissor de informação e do conhecimento, que é produzido pelo sujeito e pela comunidade, a coletividade, da qual faz parte. Para ela, são as memórias que possibilitam o acesso ao passado. Assim, este passado pode ser acessado, revivido e reconstruído quando se acionam os diversos mecanismos e ambientes da memória, os quais acolhem vivências de caráter histórico, religioso, biográfico e traumático.

Nesse ínterim, no samba-enredo em análise, variados espaços podem ser localizados - África, navio, oceano Atlântico, Brasil, Bahia, Maranhão, São Luís, todos são ocupados, em algum momento, por Agotime/Maria Mineira Naê. Assim, pode-se compreender tais espaços como possibilitadores de (re)construção e ressignificação de suas memórias individual e coletiva, como discorre também Halbwachs. No eixo dessa discussão, segundo Mortari (2015), citando Paul Gilroy (2001):

[...] as culturas e as identidades formadas no Novo Mundo são indissociáveis da experiência da escravidão, dos fluxos e trocas culturais através do Atlântico. Nesta perspectiva, as regiões de portos são espaços importantes por se caracterizarem por serem multiculturais, de contato, de mistura, de movimento, que representam entre o local e o 
global. O navio, por sua vez, é o canal de comunicação entre os diferentes mundos (MORTARI, 2015, p. 139).

Diante do exposto, o navio não apenas transporta o corpo negro traficado, escravizado, comercializado, mas comunica, como afirma a autora, a diferentes partes do mundo o que esses corpos carregam em si - um continente, países, culturas e histórias.

Retomando a ideia dos lugares acima mencionados como espaços de construção e ressignificação de memórias, que, por sua vez, são mecanismos indispensáveis à renovação da cultura por estarem atrelados não somente ao indivíduo, como a todo o grupo, ou seja, a coletividade, a teórica Aleida Asmann, no texto Espaços da recordação (2011), argumenta sobre a relação entre memória e os lugares, em outros termos, discorre sobre a importância dos ambientes, dos espaços da memória que fixam os acontecimentos vivenciados.

Desse modo, o seu lugar de origem, a África, pode ser concebida como lugar de memória das gerações, pois lá estão os seus antepassados, as suas práticas sociais, históricas e religiosas-"Agotime no clã de Daomé/E na luz de seus voduns/Existia um ritual de fé" (DÉO, CARUSO, CLEBER E OSMAR, 2001). Ademais, o continente africano, a Casa das Minas, a própria natureza, também podem ser considerados como lugares sagrados da memória, tendo em vista serem utilizados como espaços para exaltação aos orixás e para as realizações ritualísticas e cultos.

No que tange aos lugares traumáticos, estes podem ser representados pelo navio e pelo Atlântico, pois segundo a autora Asmann (2011), esses lugares servem e serviram, considerando os sujeitos serem os negros traficados e escravizados, de palco para a dor e para o sofrimento. Destarte, durante o processo de travessia, devido às condições a que foram submetidos, muitos negros acabaram mortos e lançados às águas. Aos que no navio ficavam, restavam as memórias traumáticas, revestidas pela dor da morte, pela revolta e, ao mesmo tempo, tinham que ter a esperança de alcançar novos lugares onde pudessem reconstruírem-se das sequelas dos traumas.

A memória, evocada e acionada não somente pelos espaços citados, mas por variados mecanismos, tais como a dança, a culinária e a religião, permitiram a reconstrução de suas marcas culturais e identitárias. Memórias que são do sujeito 
e da comunidade na qual está inserido. Halbwachs em Memória coletiva (2006), discorre a respeito da memória como mecanismo de (re)construção dessas marcas. Para o autor, é coletiva porque o sujeito que rememora não vive no isolamento, ao contrário, ele é parte da comunidade, agindo, interagindo e transformando-a, do mesmo modo que os acontecimentos rememorados estão situados na vivência em coletividade. Para o autor, isso é resultado de:

Nossas lembranças permanecem coletivas e nos são lembradas por outros, ainda que se trate de eventos em que somente nós estivemos envolvidos e objetos que somente nós vimos. Isso acontece porque jamais estamos sós. Não é preciso que outros estejam presentes, materialmente distintos de nós, porque sempre levamos conosco e em nós certa quantidade de pessoas que não se confundem (HALBWACHS, 2013, p. 30).

Diante da argumentação exposta, pode-se compreender que, Agotime/Maria Mineira Naê, assim como outros africanos que compartilharam a experiência do tráfico, do deslocamento e da diáspora, reinventaram e ressignificaram seus lugares de origem e todos os demais elementos culturais que comportam esses espaços, através das histórias de suas famílias, das memórias acionadas por diversos aspectos, como os lugares aqui identificados, pois traziam, além do corpo nu, muitos rastros e resíduos dos cantos, da dança, de sua história e de sua cultura, e aqui aquilombaram-se.

\section{Palavras finais}

Refletir a respeito da saga de negros e negras enredada, seja na literatura, seja na música, na pintura, no cinema, ou no próprio universo do carnaval, que coaduna diferentes linguagens e práticas culturais, possibilita-nos conhecimento e a compreensão de fatos e acontecimentos relacionados à vida e à história desses sujeitos. As discussões tecidas aqui nos permitiram compreender como se dá o processo diaspórico e também como identificar os espaços da memória trazidos pelos sujeitos que fizeram a travessia pelas águas do Atlântico Negro.

Assim sendo, considerando as argumentações aqui desenvolvidas, podemos inferir que a narrativa histórica dos negros não pode nem deve ser 
resumida somente à escravidão, à dor, ao sofrimento, ao navio, ao Atlântico; mais além desses universos têm-se uma história de luta, de resistência contra um regime aprisionador e opressor decorrente do processo de colonização e escravização, materializado pelos senhores de escravos. É uma história de (re)construção de novos espaços pelo viés memorialista.

Portanto, as reflexões desenvolvidas demonstraram que, uma vez deslocados de suas raízes, os negros diaspóricos utilizaram-se de variados mecanismos, não somente da dança, da culinária, das práticas religiosas, mas das memórias individuais e coletivas dessas manifestações, incluindo os cantos, as festas, os lugares de afetividade, sejam locais das gerações, sejam ambientes sagradas ou locais do trauma, que agem como processo de acionamento dos elementos que ressignificam os lugares de origem, que servem, também, para a ressignificação de si em suas escrevivências.

\section{Referências}

ASSMANN, Aleida. Espaços da recordação - formas e transformações da memória cultural. Campinas:UNICAMP, 2011.

BHABHA, Homi K. O local da cultura. Tradução Myriam Ávila, Eliana Lourenço de Lima Reis, GlaúciaRenate Gonçalves. Belo Horizonte: UFMG, 2013.

GILROY, Paul. O atlântico negro: modernidade e dupla consciência. Rio de Janeiro: Editora 34, 2012.

GLISSANT, Edouard. Introdução à poética da diversidade. Tradução de Enilce do Carmo Albergaria Rocha. Juiz de Fora: Editora UFJF, 2005.

HALBWACHS, Maurice. A memória coletiva. 2. ed. São Paulo: Centauro, 2013.

LOPES, Nei; SIMAS, Luiz Antonio. Dicionário da história social do samba. Rio de Janeiro: Civilização Brasileira, 2015.

MORTARI, Claudia. Pensando a diáspora africana: algumas questões. In. MORTARI, Claudia. Introdução aos estudos africanos e da diáspora. (Org). Florianópolis: DIOSEC: UDESC, pp. 139-148.

MUSSA, Alberto; SIMAS, Luiz Antonio. Samba de enredo: história e arte. Rio de Janeiro: Civilização Brasileira, 2010. 
SANDRONI, Carlos. Feitiço decente: transformações do samba no Rio de Janeiro (1917-1933). 2.ed. ampl. Rio de janeiro: Zahar, 2012.

\section{Site pesquisado}

Galeria do samba - http://www.galeriadosamba.com.br/escolas-de-samba/beijaflor-de-nilopolis/2001/. 